\title{
THE EFFECT OF EXTRACELLULAR ACIDOSIS ON THE BEHAVIOUR OF MESENCHYMAL STEM CELLS IN VITRO.
}

\author{
A. Massa ${ }^{1,2,}$, F. Perut ${ }^{1, \S}$, T. Chano ${ }^{3}$, A. Woloszyk ${ }^{4}$, T.A. Mitsiadis ${ }^{4}$, S. Avnet ${ }^{1, \S}$ and N. Baldini ${ }^{1,2, \S, *}$ \\ ${ }^{1}$ Istituto Ortopedico Rizzoli, Orthopaedic Pathophysiology and Regenerative Medicine Unit, Bologna, Italy \\ ${ }^{2}$ University of Bologna, Department of Biomedical and Neuromotor Sciences, Bologna, Italy \\ ${ }^{3}$ Department of Clinical Laboratory Medicine, Shiga University of Medical Science, Otsu, Shiga, Japan \\ ${ }^{4}$ University of Zurich, Orofacial Development and Regeneration, Institute of Oral Biology, Zurich, Switzerland \\ $\S$ These authors contributed equally
}

\begin{abstract}
The stem cell fraction of a cell population is finely tuned by stimuli from the external microenvironment. Among these stimuli, a decrease of extracellular $\mathrm{pH}(\mathrm{pHe})$ may occur in a variety of physiological and pathological conditions, including hypoxia and inflammation. In this study, by using bone marrow stem cells and dental pulp stem cells, we provided evidence that extracellular acidosis endows the maintenance of stemness in mesenchymal cells. Indeed, continuous exposure for $21 \mathrm{~d}$ to low $\mathrm{pHe}$ (6.56.8) conditions impaired the osteogenic differentiation of both cell types. Moreover, the exposure to low $\mathrm{pHe}$, for 1 and up to $7 \mathrm{~d}$, induced the expression of stemness-related genes and proteins, drove cells to reside in the quiescent G0 alert state and enhanced their ability to form floating spheres. The pre-conditioning with extracellular acidosis for $7 \mathrm{~d}$ did not affect the differentiation potential of dental pulp stem cells since, when the cells were cultured again at physiological $\mathrm{pHe}$, their multilineage potential was almost unmodified.

Our data provided evidence of the role of extracellular acidosis as a modulator of the stemness of mesenchymal cells. This condition is commonly found both in systemic and local bone conditions, hence underlining the relevance of this phenomenon for a better comprehension of bone healing and regeneration.
\end{abstract}

Keywords: mesenchymal stem cells, dental pulp stem cells, extracellular $\mathrm{pH}$, stemness, osteogenic differentiation.

*Address for correspondence:

Nicola Baldini, MD

Istituto Ortopedico Rizzoli, Orthopaedic Pathophysiology and Regenerative Medicine Unit Via di Barbiano 1/10, 40136 Bologna, Italy

Telephone number: +390516366897

Fax number: +390516366974

Email: nicola.baldini@ior.it

\section{Introduction}

Maintenance of acid-base homeostasis in the cytoplasm and in extracellular fluids is essential for the physiological activities of cells and tissues (Hamm et al., 2015). Extracellular $\mathrm{pH}(\mathrm{pHe}$ ) modulates multiple cell functions, including proliferation, cloning efficiency, metabolism and differentiation (Hamm et al., 2015; McAdams et al., 1997). Buffering of plasma $\mathrm{pH}$ is maintained in a strict range (7.35-7.45) and the $\mathrm{pH}$ of interstitial fluids and/or extracellular $\mathrm{pH}$ are finely tuned within a well-defined gradient, depending on the cell type and tissue specificity (Gerweck et al., 1996; Martin and Jain, 1994). Due to technical limitations, pHe levels in bone tissues have not been clearly established. Mineral deposition requires a pHe of about 8 for optimal alkaline phosphatase activity and hydroxyapatite precipitation (Arnett, 2010; Castro et al., 2012). However, osteoclasts locally create a strong extracellular acidification ( $\mathrm{pH} 4.7)$ that is necessary to dissolve mineralised matrix and resorb bone. If abnormal acidification occurs, mineral deposition and osteoblast differentiation and functions are inhibited (Brandao-Burch et al., 2005; Takeuchi et al., 2013; Orriss et al., 2015), whereas osteoclast formation and activity are enhanced (Arnett, 2010). Indeed, a number of systemic conditions, such as chronic kidney and respiratory diseases, anaerobic exercise, excessive protein intake, diabetes and aging are associated with metabolic acidosis, influencing bone homeostasis (Kraut and Madia, 2010). Furthermore, local diseases, such as infection, trauma and cancer, all promoting interstitial acidosis (Martin and Jain, 1994; Dong et al., 2013), are associated with altered bone structure and density. Thus, it is conceivable that $\mathrm{pHe}$ changes in bone may not only affect differentiated cells but also stem cell populations. Indeed, the acidification that usually occurs in the early phases of fracture repair (Claes et al., 2012) has been suggested to be a stress stimulus that can be perceived by stem cells and a driving force for regeneration through the release of growth factors that act on the stem cell fraction to repair bone (Chakkalakal et al., 1994). It has been shown that the hypoxic and thus acidic environment of the bone marrow haematopoietic stem cell niche is essential for the fate of stem cells, thus suggesting an association between local acidosis and stemness of mesenchymal stem cells (Mohyeldin et al., 2010). Notably, in cancer stem cells, extracellular acidosis and lysosomal acidification have been associated 
with stemness (Hjelmeland et al., 2011; Salerno et al., 2014). Nevertheless, following the controversial original report by Obokata et al. (2014) fostering this hypothesis for normal stem cells and its subsequent withdrawal, the effect of extracellular acidosis on stemness is still an open issue. In this study, we explored the hypothesis that $\mathrm{pHe}$ is fundamental for cell physiology and function of bone and sought for the role of $\mathrm{pHe}$ in bone regeneration by modulating the stemness of mesenchymal cells.

\section{Materials and Methods}

\section{Cell culture}

Dental pulp stem cells (DPSC) were obtained from the dental pulp of healthy teeth extracted for orthodontic treatment (from 5 different donors). The procedure was approved by the Institutional Review Board of the Centre of Dental Medicine, University of Zürich and performed after the written informed consent from the guardians of those underage subjects was obtained. DPSC samples were irreversibly anonymised. After removal of the dental pulp from the tooth, DPSC were isolated, expanded and characterised, as previously described (Tirino et al., 2012).

Bone marrow-derived mesenchymal stem cells (BMMSC) were purchased from the American Type Culture Collection (from three different donors, adult males aged 38-55, ATCC, Manassas, VA, USA). During the expansion phase and when cultured under basal conditions, DPSC and BM-MSC were maintained in Dulbecco's Modified Eagle's Medium/Nutrient Mixture F-12 Ham (DMEM/
F12) (Sigma-Aldrich, Milan, Italy), supplemented with $10 \%$ foetal bovine serum (FBS) (Sigma-Aldrich), penicillin $(100 \mathrm{U} / \mathrm{mL})$ and streptomycin $(100 \mathrm{mg} / \mathrm{mL})$ (Thermo Fisher Scientific, Waltham, MA, USA) at $37^{\circ} \mathrm{C}$ and $5 \% \mathrm{CO}_{2}$. The medium was changed twice a week. After the expansion phase, for all the different assays, DPSC or BM-MSC were always used at passage 3 or 4 and maintained at different conditions depending on the specific assay (Fig. 1). The specific pHe of the culture medium $(6.5,6.8,7.1$ or 7.4$)$ was maintained by using different concentrations of sodium bicarbonate, according to the Henderson-Hasselbach equation. At the end-point of each experiment, the final $\mathrm{pH}$ in the supernatant was always measured with a digital $\mathrm{pH}$-meter $(6230 \mathrm{~N}$, Jenco, San Diego, CA, USA) to ascertain the maintenance of the $\mathrm{pH}$ value along the incubation time.

\section{Osteogenic differentiation}

To evaluate the effect of extracellular acidosis on osteogenic differentiation, after the expansion phase, DPSC and BM-MSC were seeded in duplicate at a density of $1 \times 10^{4}$ cells $/ \mathrm{cm}^{2}$ in basal culture conditions and then synchronised in the G0 phase of the cell cycle by a $48 \mathrm{~h}$ incubation in serum starved medium $(0.2 \% \mathrm{FBS})$. Then, cells were cultured in osteogenic medium [DMEM/F12 medium with $10 \% \mathrm{FBS}, 50 \mathrm{mg} / \mathrm{mL} \mathrm{L}$-ascorbic acid 2-phosphate, $10^{-8} \mathrm{M}$ dexamethasone (Sigma-Aldrich)] at different $\mathrm{pHe}(6.5,6.8,7.1$ or 7.4$)$.

Total RNA was isolated after 7 (T1) and $14 \mathrm{~d}$ (T2) with the NucleoSpin RNA II (Macherey-Nagel, Düren, Germany). Total mRNA was reverse transcribed with the Advantage

\section{CONDITIONING WITH ACIDOSIS}

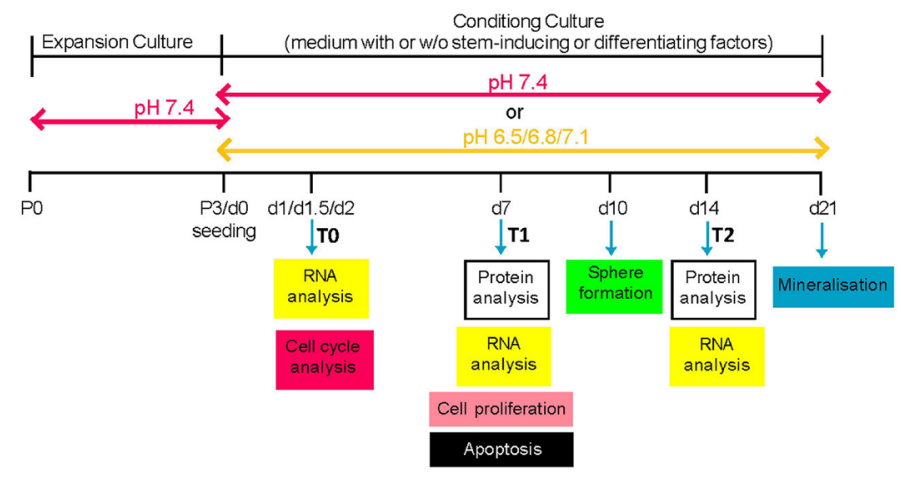

Fig. 1. Graphical scheme of the time schedule of the different assays performed with conditioning or pre-conditioning with extracellular acidosis. d, days; P, passage; $\mathrm{T}$, time. We assumed $\mathrm{pH} 7.1$ as an acidic condition since we considered the physiological value of $\mathrm{pH} 7.4$ as reference $\mathrm{pH}$. In addition to the experimental conditions showed in the scheme, for cell cycle, apoptosis and mineralisation assays, we also performed a $48 \mathrm{~h}$ pre-incubation period in starving condition $(0.02 \% \mathrm{FBS})$ at $\mathrm{pH} 7.4$ after $\mathrm{d} 0$. 
RT-for-PCR Kit (Life Technologies, Monza, Italy). The expression of type I collagen (COL1A1) (NM_000088.3), alkaline phosphatase (ALPL) (NM_000478.3), Runtrelated transcription factor 2 (RUNX2) (NM_001024630.2) and Homo sapiens SRY (sex determining region Y)-box 9 (SOX9) (NM_000346.3) was evaluated by using the Light Cycler instrument (Roche Diagnostics). $1 \mu \mathrm{g}$ of cDNA was amplified and the Universal ProbeLibrary system used (Roche Applied Science, Monza, Italy). Probes and primers were selected by using web-based assay design software ProbeFinder (https://www.roche-applied-science.com): COL1A1-fwd 5'-CCCCTGGAAAGAATGGAGAT-3'; COL1A1-rev 5'-AATCCTCGAGCACCCTGA-3'; ALPL-fwd 5'-GGGTCAGCTCCACCACAA-3'; ALPLrev 5'-GCATTGGTGTTGTACGTCTTG-3'; RUNX2fwd 5'-GTGCCTAGGCGCATTTCA-3'; RUNX2-rev 5'-CACCTGCCTGGCTCTTCTTA-3'; SOX9-fwd 5'-GTACCCGCACTTGCACAAC-3'; SOX9-rev 5'-TCGCTCTCGTTCAGAAGTCTC-3'. Results were expressed as ratio between the gene of interest and the reference gene rRNA18s (X03205.1) (rRNA18s-fwd 5'-GCAATTATTCCCCATGAACG-3'; rRNA18s-rev 5'-GGGACTTAATCAACGCAAGC-3') according to the $2^{-\Delta \Delta \mathrm{CT}}$ method (Livak et al., 2001). Conditioned medium and cell lysates were collected after 7 (T1) and $14 \mathrm{~d}$ (T2). Cell lysates were obtained by treating cells with RIPA lysis buffer (1 \% Triton X-100, $10 \%$ Na-deoxycholate, $5 \mathrm{M} \mathrm{NaCl}, 1 \mathrm{M}$ Tris-HCl, pH 7.4, 0.5 M EGTA, pH 8, $1 \mathrm{M} \mathrm{NaF}$ ) and protease inhibitors (Roche, Milan, Italy) for 20 min at $4{ }^{\circ} \mathrm{C}$. The secretion of Type I C-terminal collagen propeptide and osteocalcin content were quantified by Metra CICP ELISA kit (Quidel, San Diego, CA, USA) and N-Mid Osteocalcin kit (Pantec, Turin, Italy), respectively. Pro-collagen type I and osteocalcin levels $(\mathrm{ng} / \mathrm{mL})$ in the conditioned medium or in the cell lysates were normalised to total protein.

The deposition of mineralised matrix was evaluated after $21 \mathrm{~d}$ of treatment with medium at different $\mathrm{pHe}$. Cells were fixed in $3.7 \%$ paraformaldehyde for $20 \mathrm{~min}$ and stained with $2 \%$ alizarin red at $\mathrm{pH} 4.2$ (Sigma-Aldrich) for $1 \mathrm{~h}$ at room temperature (RT). Then, the staining was eluted with a solution of $10 \%$ cetylpyridinium chloride $(\mathrm{CPC})(\mathrm{p} / \mathrm{v})($ Sigma-Aldrich) and the absorbance at $570 \mathrm{~nm}$ was quantified by using a microplate-reader (Tecan Infinite F200pro, Männedorf, Switzerland). The results were expressed as mean optical density (OD).

\section{RNA-seq analysis}

After the expansion phase, BM-MSC were seeded at a density of $1 \times 10^{4}$ cells $/ \mathrm{cm}^{2}$ in basal culture conditions. Then, they were incubated for $24 \mathrm{~h}$ (T0) in complete medium at low $\mathrm{pHe}$ (6.5) or at physiological pHe (7.4). At the end of the incubation period, total RNA was extracted using guanidinium thiocyanate-phenol-chloroform and quantified with Bioanalyzer (Agilent, Santa Clara, USA) following the manufacturer's instructions. For all samples, RIN (RNA integrity number) and A260/A280 ratios of total RNA were 10 and over 1.8 , respectively. The library of template molecules for high throughput DNA sequencing was converted from the total RNA using TruSeq RNA Sample Prep Kit v2, following the manufacturer's protocol (Illumina, San Diego, CA, USA) and quantified with Bioanalyzer (Agilent), following the manufacturer's instruction. The library ( $3 \mathrm{pM})$ was subjected to cBot clonal amplification system for cluster generation on a Single Read Flow Cell v4 with a cluster generation instrument (Illumina). Sequencing was performed on a Genome Analyzer GAIIx for 76 cycles using Cycle Sequencing v4 reagents (Illumina). Image analysis and base calling were performed using Off-Line Basecaller Software 1.6 (Illumina). Reads were aligned using ELAND v2 of CASAVA Software 1.7 (Illumina) with the sequence data sets. Human genome build 19 (hg19) was downloaded from genome browser (http://genome.ucsc.edu/), University of California, Santa Cruz, as the analytic reference. Transcript coverage for every gene locus was calculated from the total number passing filter reads that mapped to exons and quantified with quantile normalisation algorithm, by Avadis NGS software (version1.5, Strand Scientific Intelligence Inc). The filtering was performed using default parameters. All data were deposited in DDBJ/EMBL/ GenBank under DRA004087 and DRA004091.

\section{Sphere-forming assay}

After the expansion phase, DPSC and BM-MSC were seeded and cultured in DMEM-F12 medium in 48-well plates $(15,000$ cells/well) coated with poly-HEMA (Sigma-Aldrich) in anchorage-independent conditions. DMEM-F12 complete medium was used at different $\mathrm{pHe}$ $(6.5,6.8,7.1$ or 7.4$)$. Progesterone $(20 \mathrm{nM})$, putresceine $(10 \mathrm{mg} / \mathrm{mL})$, sodium selenite $(30 \mathrm{nM})$, apo-transferrin (100 $\mathrm{mg} / \mathrm{mL}$ ) and insulin $(25 \mathrm{mg} / \mathrm{mL})$ (Sigma-Aldrich) were added to complete the medium. Fresh human epidermal growth factor $(20 \mathrm{ng} / \mathrm{mL})$ and basic fibroblast growth factor $(10 \mathrm{ng} / \mathrm{mL})($ PeproTech, London, UK) were added twice a week. After $10 \mathrm{~d}$, bright field images were acquired. Only spheres with a diameter larger than $20 \mu \mathrm{m}$ were counted. Analysis of cell diameter was performed by using the NIS Element Image Software BR 4,00,00 (Nikon Instruments).

\section{Gene expression}

After the expansion phase, DPSC and BM-MSC were seeded and cultured at different $\mathrm{pH}$ for mRNA analysis. Total RNA from DPSC and BM-MSC, cultured for $24 \mathrm{~h}$ (T0) and $7 \mathrm{~d}$ (T1) in DMEM complete medium at different $\mathrm{pH}$, was isolated and reverse transcribed by NucleoSpin RNA II and Advantage RT-for-PCR Kit, as described above. The expression of mRNA for Octamer-binding Transcription Factor 4 (OCT4) (NM_002701.4), SRY-box2 (SOX2) (NM_003106.3), v-myc avian myelocytomatosis viral oncogene homolog (c-MYC) (NM_002467.4), Kruppel-like factor 4 (KLF4) (NM_004235.4), nestin (NM_006617) and nerve growth factor receptor (p75/ NGFR) (NM_002507) was evaluated by using the Light Cycler instrument (Roche Diagnostics). Probes and primers were selected by using web-based assay design software (ProbeFinder https://www.roche-applied-science. com): OCT4-fwd 5'-CTTCGCAAGCCCTCATTTC-3'; OCT4-rev 5'-GAGAAGGCGAAATCCGAAG-3'; SOX2-fwd 5'-GGGAATGGACCTTGTATAG-3'; SOX2-rev 5'-GCAAAGCTCCTACCGTACCA-3'; c-MYC-fwd 5'-GCTGCTTAGACGCTGGATTT-3'; 
c-MYC-rev 5'-TAACGTTGAGGGGCATCG-3'; KLF4fwd 5'-CCATCTTTCTCCACGTTCG-3'; KLF4-rev 5'-AGTCGCTTCATGTGGGAGAG-3'; nestin-fwd 5'-TGCGGGCTACTGAAAAGTTC-3'; nestin-rev 5'-TGTAGGCCCTGTTTCTCCTG-3'; p75/NGFR-fwd 5'-CAGAGCCTGCATGACCAG-3'; p75/NGFR-rev 5'-GCAGAGCCGTTGAGAAGC-3'. Results were expressed as ratio between the gene of interest and rRNA18s (X03205.1), as described above.

\section{Proteome profiler array}

To assess the protein expression in DPSC spheres, after the expansion phase, DPSC were cultured as described in the sphere forming assay and maintained at $\mathrm{pHe} 6.5$ or $\mathrm{pHe} 7.4$ for $7 \mathrm{~d}$. Once the spheres were formed, the expression of stem cell-related markers in DPSC spheres was assessed by the Human Stem Cell Array C1 Kit (Raybiotech, Norcross, GA, USA). Protein lysates were quantified by BCA assay, and equally loaded as duplicates. The signal of each spot on the membranes was quantified by a dedicated software for densitometric evaluation, according to the manufacturer's instruction (VisionWorksLS Analysis Software, Biospectrum, UVP, Upland, CA, USA).

\section{Cell proliferation}

After the expansion phase, DPSC were seeded in 6-well plates $(100,000$ cells/well) in DMEM/F12 complete medium. After $24 \mathrm{~h}$, the medium was changed with complete medium at different $\mathrm{pHe}(6.5,6.8,7.1$ or 7.4$)$. Cell growth was evaluated after $7 \mathrm{~d}$ of culture by direct cell counting and by using vital staining with erythrosine dye.

\section{Ki67 staining}

After the expansion phase, DPSC and BM-MSC were seeded on glass chamber slides $(8,000$ cells/ wells). Synchronisation in the G0 phase of the cell cycle was obtained by starvation for $48 \mathrm{~h}$ (Rosner and Hengstschläger, 2011). Then, cells were cultured with DMEM complete medium at different $\mathrm{pHe}(6.5,6.8,7.1$ or 7.4) for $36 \mathrm{~h}$. Subsequently, cells were fixed with $3.7 \%$ paraformaldehyde (Sigma-Aldrich) in PBS for $20 \mathrm{~min}$ at RT and permeabilised with HEPES-triton for $5 \mathrm{~min}$. Ki67 was revealed with a monoclonal anti-Ki67 antibody ( $1: 75$, DAKO, Santa Clara, CA, USA). After washing, cells were incubated with the secondary antibody Alexa Fluor $488 \mathrm{~nm}$ ( 1 : 1000, Life Technologies) and $0.02 \%$ Evans blue for $1 \mathrm{~h}$. Cells were analysed using a fluorescence microscope. The Ki67 index was determined as the percentage of cells with Ki-67-positive nuclear staining in respect to the total cell population.

\section{Cell cycle analysis}

After the expansion phase, DPSC were synchronised in the G0 phase of the cell cycle by starvation, as described for the Ki67 assay. After starvation, cells were cultured for $36 \mathrm{~h}$ in DMEM medium with $10 \% \mathrm{FBS}$ at different $\mathrm{pHe}(6.5,6.8,7.1$ or 7.4$)$. At the end-point, cells were incubated with $77 \mathrm{mM}$ 5-BrdU (Sigma-Aldrich) for $20 \mathrm{~h}$ at $37^{\circ} \mathrm{C}$, washed and fixed with $75 \%$ ethanol for $20 \mathrm{~min}$ on ice. Partial DNA denaturation was performed by incubating cells in $\mathrm{HCl}$, followed by neutralisation with Sodium tetraborate. Then, samples were incubated with a mouse monoclonal anti-bromodeoxyuridine (BrdU) FITC antibody (BD Bioscience, Milan, Italy), washed, stained with $2.5 \mathrm{mg} / \mathrm{mL}$ propidium iodide (PI) (Sigma-Aldrich) and analysed. Monoparametric and biparametric analyses were performed using the WinMDI 2.7 software by using low-cytometer EPICS XL-MCL (Beckman Coulter, Milan, Italy). The DNA content and BrdU incorporation during the S-phase were determined by simultaneous analysis of PI for the total DNA content and of FITC-conjugated anti-BrdU.

\section{Cell size}

After the expansion phase, DPSC and BM-MSC were synchronised by starvation as described for the Ki-67 assay. Then, cells were incubated for $36 \mathrm{~h}$ in DMEM/F12 plus $10 \% \mathrm{FBS}$ at different $\mathrm{pHe}(6.5,6.8,7.1$ or 7.4$)$. At the endpoint, for each condition, a cell suspension of 10,000 cells was cytospinned on a glass slide. Bright field images were acquired through an optical microscope with a $4 \times$ objective lens. Quantification of the cell diameter was performed by using the NIS Element Image Software BR 4.00.00.

\section{Apoptosis analysis}

After the expansion phase, and after seeding and starvation, as described for the Ki67 assay, DPSC and BM-MSC were exposed to cell medium at $\mathrm{pHe} 6.5$ or $\mathrm{pHe} 7.4$. After $7 \mathrm{~d}$, cells were fixed and permeabilised with $0.5 \% \mathrm{PBS} /$ Triton-X-100. Then, cells were incubated for $10 \mathrm{~min}$ with $2.25 \mathrm{mg} / \mathrm{mL}$ of Hoechst 33258 (Sigma) for nuclear staining. Treatment with $2 \mu \mathrm{M}$ staurosporine for $24 \mathrm{~h}$ was used as a positive control. Eight representative fields per sample were used for cell counting and observed by fluorescence microscope with a $20 \times$ objective lens. Results were expressed as percent of cells with apoptotic nuclear bodies in respect to the total number of cells.

\section{Clonogenic ability}

After the expansion phase, DPSC were cultured for $7 \mathrm{~d}$ in basal medium at different pHe (6.5 or 7.4). At the end of the pre-conditioning period, DPSC were detached, seeded at a density of 16 cells $/ \mathrm{cm}^{2}$ and cultured in DMEM/F12 medium at $\mathrm{pHe}$ 7.4. After $10 \mathrm{~d}$, colonies were stained with crystal violet dye (25\% crystal violet dye in $20 \%$ methanol for $10 \mathrm{~min}$ at RT) (Sigma). Only aggregates with more than 20 cells were counted by using an optical microscope. Results were shown as colony-forming units (CFU) frequency (i.e. number of CFU per $10^{2}$ cells).

\section{Multilineage potency}

After the expansion phase, DPSC were pre-conditioned by a $7 \mathrm{~d}$ culture in DMEM/F12 complete medium at different pHe (6.5 or 7.4). Then, DPSC were detached and seeded to evaluate their multilineage potency.

To evaluate the ability to deposit mineralised matrix, DPSC were seeded at the density of 100,000 cells/well in 6-wells plates and cultured in osteogenic medium at $\mathrm{pHe}$ 7.4. After $21 \mathrm{~d}$, cells were fixed in $3.7 \%$ paraformaldehyde (Sigma-Aldrich) for $20 \mathrm{~min}$ and calcium deposits were stained with $1 \%$ alizarin red $\mathrm{S}(\mathrm{pH} 4.2)$ 
(Sigma-Aldrich) for $1 \mathrm{~h}$ at RT. Stained mineralised matrix was observed using an optical microscope and quantified as described above.

For adipogenic differentiation, 100,000 cells/well were seeded on 6-wells plates and cultured until subconfluency.
Then, the culture medium was replaced with differentiation medium consisting of high glucose DMEM (Euroclone) pHe 7.4, supplemented with dexamethasone $(0.5 \mu \mathrm{M})$, indomethacin $(50 \mu \mathrm{M})$ and isobutylmethylxanthine (0.5 mM) (Sigma). To detect lipid accumulation, cultures
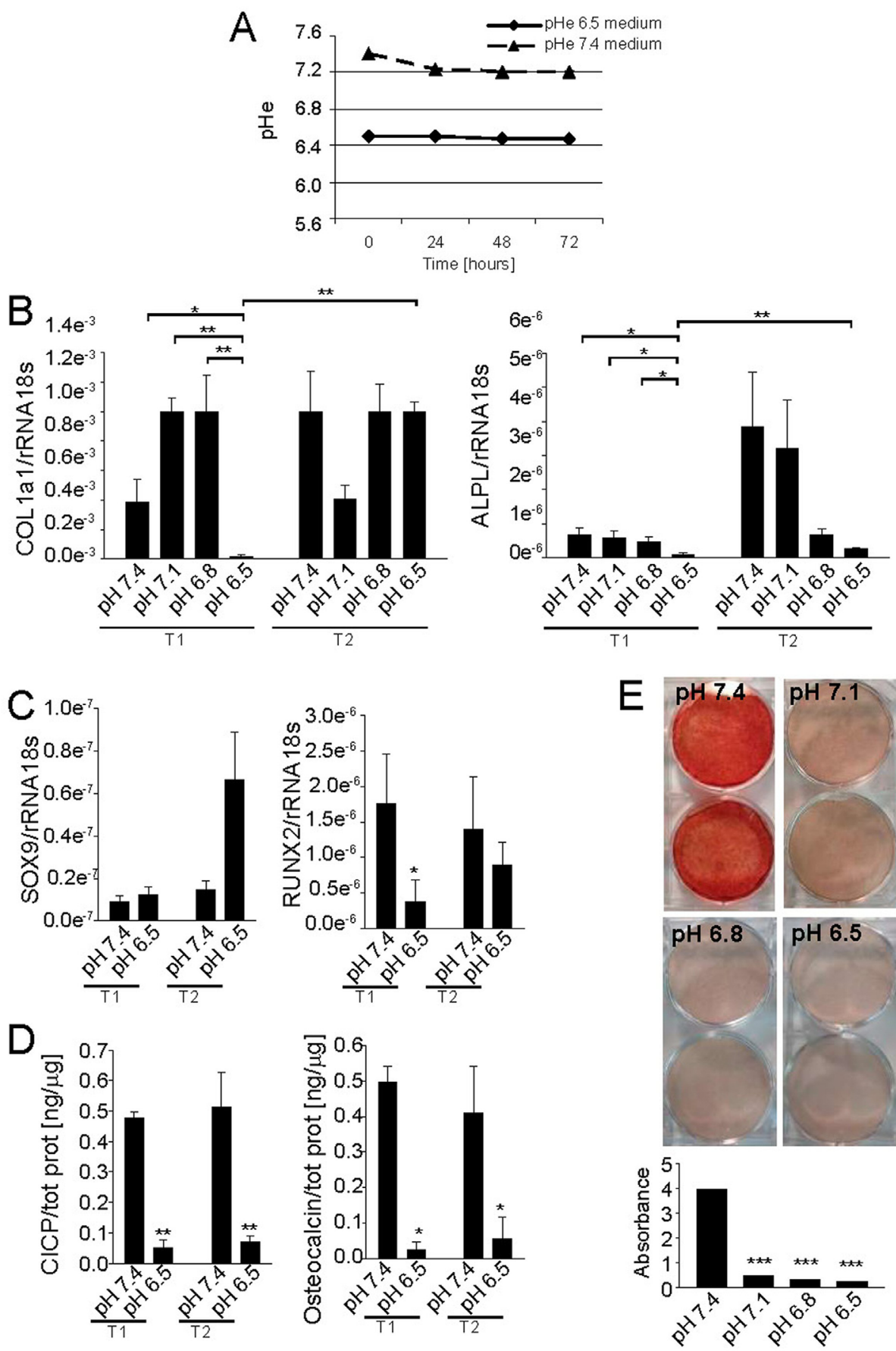

Fig. 2. Extracellular acidosis affected osteogenic differentiation and mineralisation of DPSC. Cells were seeded and incubated at the specified $\mathrm{pH}$. Data are expressed as mean $\pm \mathrm{SE}$. (A) $\mathrm{pH}$ maintenance of media with different sodium bicarbonate concentrations over the culture period. (B) Real Time PCR analysis for the expression of COL1A1 and ALPL, (C) SOX9 and RUNX2 in cells cultured at different pH for $7 \mathrm{~d}$ (T1) and $14 \mathrm{~d}$ (T2) (results obtained with three different donors and two technical replicates, $* p<0.05, * * p<0.01$ ). (D) Protein quantification of pro-collagen type I (CICP) and osteocalcin in cells cultured at different pH for $7 \mathrm{~d}$ (T1) and $14 \mathrm{~d}$ (T2) (results obtained with three different donors and two technical replicates, $* p<0.05, * * p<0.01$ ). (E) Representative pictures of alizarin red assay after $21 \mathrm{~d}$ of incubation with osteogenic medium at different $\mathrm{pH}$ (upper panel) and the respective quantification (absorbance at $570 \mathrm{~nm}$, lower panel) (results obtained with three different donors and two technical replicates, $* * * p<0.001)$. 
were fixed in $3.7 \%$ paraformaldehyde for $20 \mathrm{~min}$ and stained with $0.3 \%$ Oil Red $\mathrm{O}$ in isopropanol for $1 \mathrm{~h}$ at RT. To quantify the content of lipids, Oil Red O dye was eluted by incubation with absolute isopropanol at RT for $15 \mathrm{~min}$ under gentle shaking. The absorbance was measured at $540 \mathrm{~nm}$ with a microplate reader (Tecan Infinite F200pro). Results are expressed as OD.

DPSC were cultured in a pellet culture system to induce chondrogenic differentiation. 500,000 cells were resuspended in complete high glucose DMEM medium at $\mathrm{pHe} 7.4$, supplemented with insulin $(6.25 \mu \mathrm{g} / \mathrm{mL})$ (Roche), L-ascorbic acid 2-phosphate $(50 \mu \mathrm{M})$ and TGFß3 (10 ng/mL) (Peprotech). After $21 \mathrm{~d}$, the pellet was digested with $20 \mathrm{mM}$ sodium phosphate buffer (pH 6.8) containing $1 \mathrm{mM}$ EDTA, $2 \mathrm{mM}$ dithiothreitol and $300 \mathrm{ug} / \mathrm{mL}$ papain for $30 \mathrm{~min}$ at $60{ }^{\circ} \mathrm{C}$. The amount of sulphated glycosaminoglycans was determined by a Sulfate Glycosaminoglycan Quantification Kit (Amsbio, Abingdon, UK), according to the manufacturer's instructions. Results were normalised to the amount of total protein content and expressed as ng of sulphated glycosaminoglycan $/ \mu$ g total protein.

\section{Statistical analysis}

Statistical analysis was performed by the StatView ${ }^{\mathrm{TM}}$ 5.0.1 software for Windows (SAS Institute, Cary, NC, USA). Due to the small number of observations, data were considered as not normally distributed. Results were reported as mean \pm standard error. To evaluate gene expression, protein content/secretion, cell diameter and the percentage of apoptotic cells, we used the non-parametric Mann-Whitney $U$ test for the analysis between unpaired groups. To evaluate sphere number and volume, cell proliferation, Ki67 index, deep sequencing and protein profiler assay, we used the Wilcoxon Rank for paired analysis. Only $p<0.05$ were considered as statistically significant.

\section{Results}

\section{Extracellular acidosis impaired DPSC and BM-MSC osteogenic differentiation}

First, we verified if the culture medium $\mathrm{pH}$ values, that we adjusted to mimic different extracellular $\mathrm{pHe}$, were maintained over the incubation period. After $24 \mathrm{~h}$, the culture medium that was originally buffered at the physiological value of $\mathrm{pH} 7.4$ showed a slight decrease to pHe 7.2 (Fig. 2A), which was maintained over the culture period. For the medium originally buffered at $\mathrm{pHe} 6.5$, the $\mathrm{pH}$ value was more stable and constant at all the examined time points (Fig. 2A).

Under those experimental conditions, we confirmed, that in vitro acidic $\mathrm{pHe}$ inhibits the osteogenic differentiation of stem cells of mesenchymal origin, as shown by a significant but transient decrease of osteoblast-related genes expression and an inhibition of mineral nodule formation in DPSC (Fig. 2B-E). In particular, at T1, in cells maintained at $\mathrm{pHe} 6.5$, we observed a reduction of 20.6 and 8.3 folds of type I collagen and alkaline phosphatase mRNA expression compared to pHe 7.4 (Fig. 2B) and a reduction of 2.15 folds of Runx 2 mRNA expression at T1 that was unaffected at T2. In contrast, SOX9 expression was unaffected at T1 and showed a trend for increase at T2 (Fig. 2C). Subsequently, we confirmed the mRNA data obtained in DPSC by using specific assays for proteins related to the ECM matrix, including type I C-terminal collagen propeptide (CICP) and osteocalcin (Fig. 2D). They appeared to be dramatically decreased during the osteogenic differentiation, at both time points (Fig. 2D). Finally, we found that the formation of mineral nodules, an indirect index of osteogenic differentiation, was strongly inhibited at pHe 6.5, 6.8 and 7.1 compared to $\mathrm{pHe} 7.4$ (Fig. 2E). Similar results were obtained in BM-MSC, an additional model of mesenchymal stem cells: pro-collagen type I (CICP) and osteocalcin content were dramatically
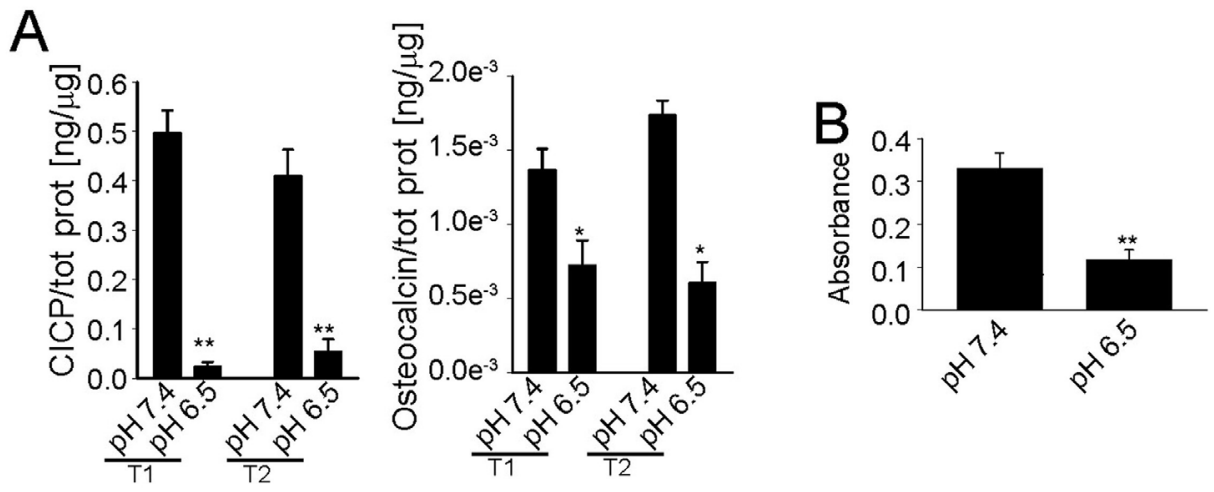

Fig. 3. Extracellular acidosis affected osteogenic differentiation and mineralisation of BM-MSC. Cells were seeded and incubated at the specified $\mathrm{pH}$. Data are expressed as mean \pm SE. (A) Protein quantification of pro-collagen type I (CICP) and osteocalcin in cells cultured at different pH for $7 \mathrm{~d}$ (T1) and $14 \mathrm{~d}$ (T2) (results obtained with three different donors and with two technical replicates; $* p<0.05, * * p<0.01$ ). (B) Quantification of alizarin red staining after $21 \mathrm{~d}$ of incubation with osteogenic medium at different $\mathrm{pH}$ (absorbance at $570 \mathrm{~nm}$ ) (results obtained with three different donors and with two technical replicates, $* * p<0.01$ ). 

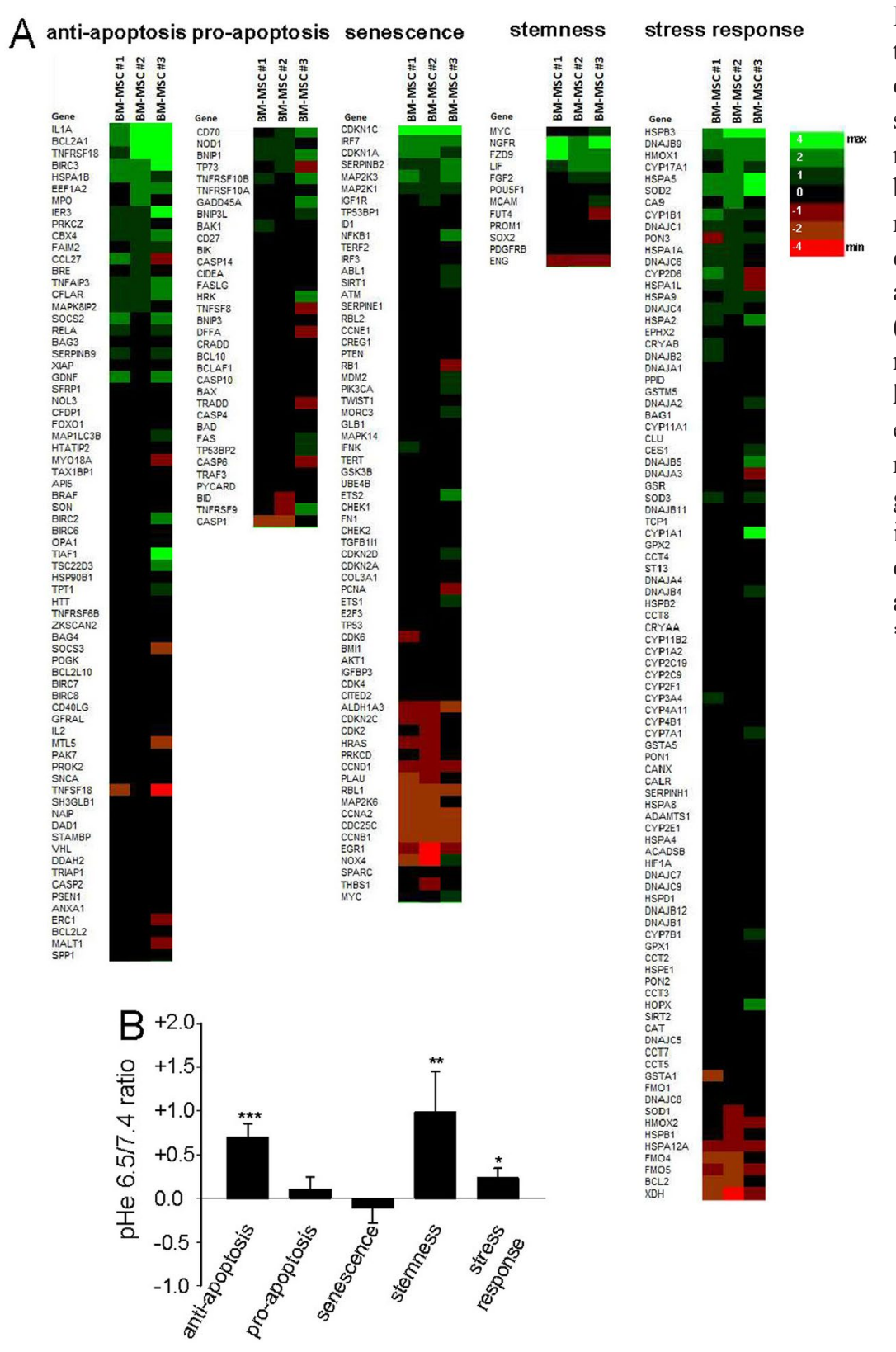

Fig. 4. Effects of short-term exposure to the acidic microenvironment on senescence, apoptosis and stemness of BM-MSC. (A) Heatmap representation of the fold increase, by deep-sequencing analysis, of the mRNA levels of BM-MSC (results obtained with three different donors) after short-term acidosis exposure (pHe 6.5), compared to physiological medium (pHe 7.4). Colours on the heat map indicate the $\log 2$ ratios of expression (representing normalised read counts). Red, downregulation; green, upregulation. (B) Clustering in gene categories of the results obtained by the deep-sequencing analysis (mean $\pm \mathrm{SE}$; $p<0.05$, $* * p<0.01, * * * p<0.001)$.
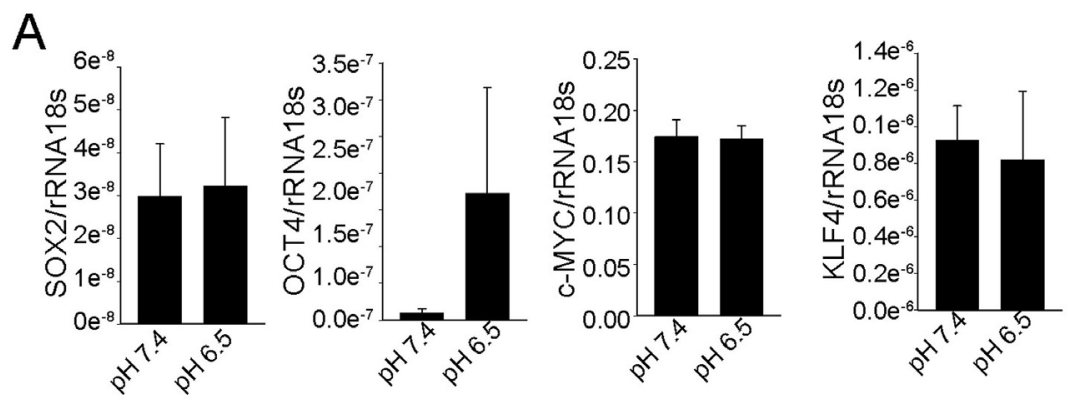

Fig. 5. Effects of short-term exposure on mesenchymal stem cells. Real Time PCR analysis of the expression of SOX2, OCT4, KLF4 and c-MYC in (A) DPSC and (B) BM-MSC, maintained at pHe 6.5 and 7.4 for $24 \mathrm{~h}$ (results obtained with three different donors and with two technical replicates, mean $\pm \mathrm{SE}$, $* p<0.05)$.
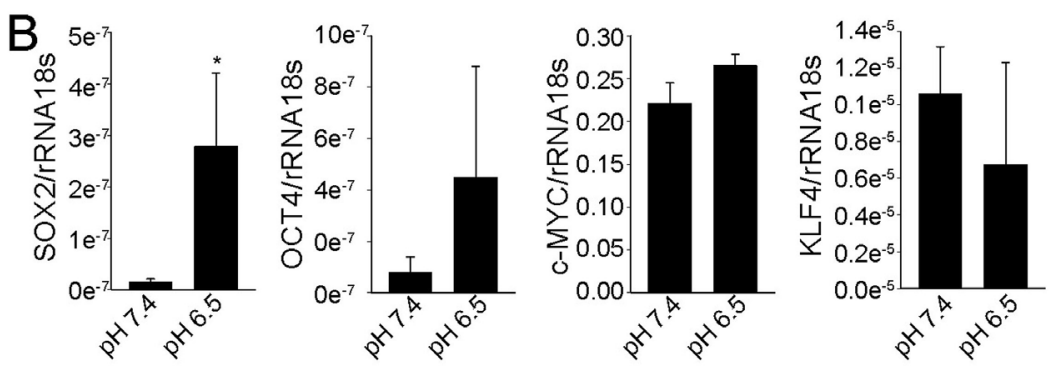
A

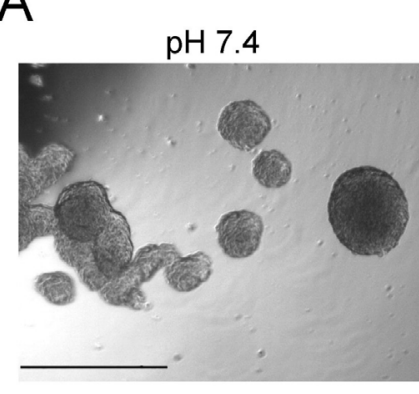

pH 6.8

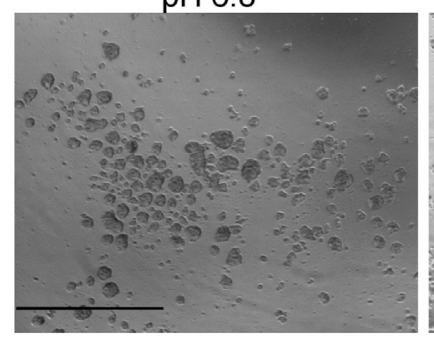

pH 7.1

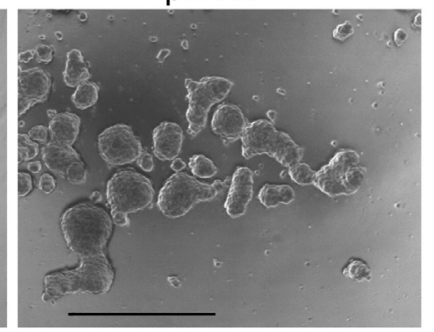

$\mathrm{pH} 6.5$

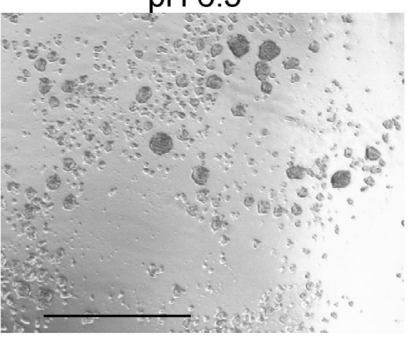

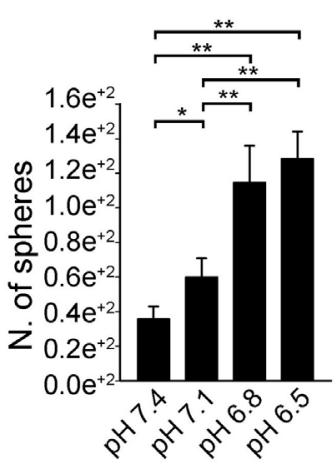

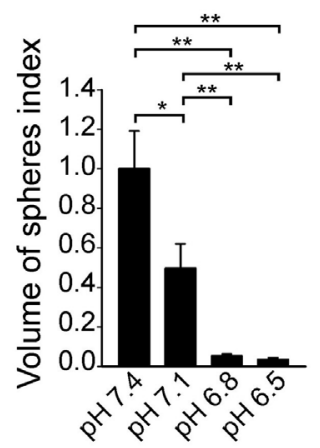

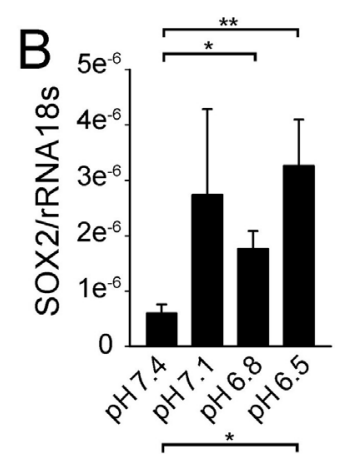
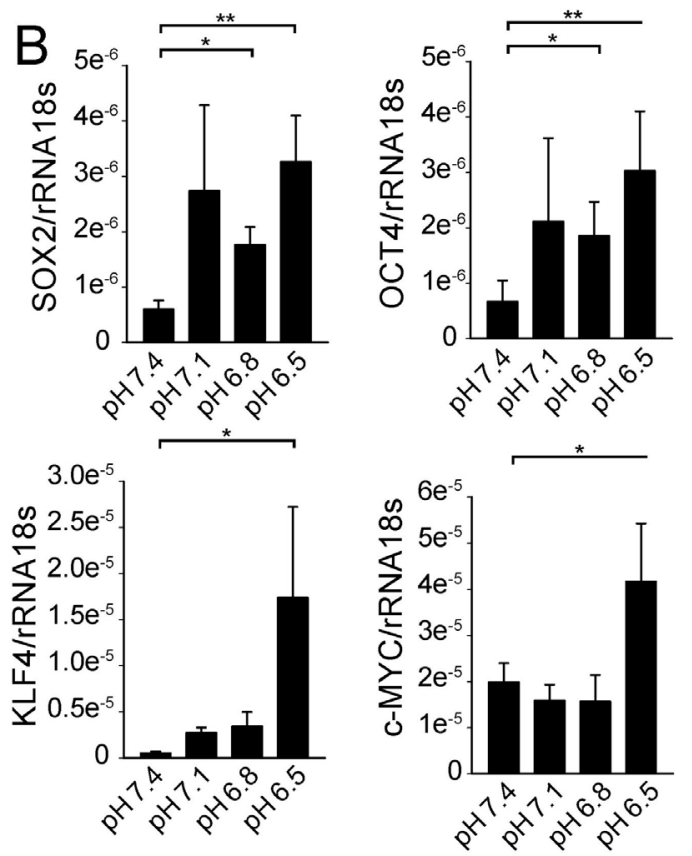

C

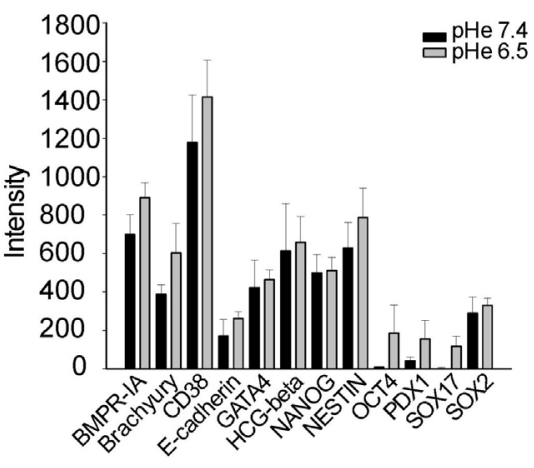

Fig. 6. Extracellular acidosis maintained the stemness of DPSC. (A) Representative images of DPSC spheres obtained after $10 \mathrm{~d}$ of culture in medium at different $\mathrm{pH}($ left panel, scale bar $=500 \mu \mathrm{m})$. Right panel, quantification of number and volume index of spheres (results obtained with three different donors and with three technical replicates, Mean $\pm \mathrm{SE}, * p<0.05, * * p<0.01)$. (B) Real Time PCR analysis of the expression of SOX2, OCT4, KLF4 and c-MYC in DPSC maintained at different $\mathrm{pH}$ for $7 \mathrm{~d}$ (results obtained with three different donors and with two technical replicates, mean $\pm \mathrm{SE}, * p<0.05, * * p<0.01$ ). (C) The stem cell markers of DPSC spheres were evaluated by proteome expression profiler and densitometric quantification (results obtained with three different donors and with two technical replicates). 
decreased at pHe 6.5 compared to pHe 7.4 (Fig. 3A) and the ability to deposit mineral nodules was significantly impaired by extracellular acidosis (Fig. 3B).

\section{Effects of short-term exposure to an acidic microenvironment on senescence, apoptosis and stemness}

To ascertain if the biological effect of short-term extracellular acidosis observed in stem cells of mesenchymal origin was a consequence of the induction of apoptosis, senescence or a modulation of stemness, we used deep-sequencing analysis for preliminary screening. Notably, the incubation of BM-MSC at a low $\mathrm{pH}$ for $24 \mathrm{~h}$ induced the significant expression of anti-apoptotic, stemness-related and stressrelated genes, whereas the expression of pro-apoptotic genes and senescence-related genes was unaffected (Fig. 4A,B).

qRT-PCR analysis of DPSC and BM-MSC partially confirmed the deep-sequencing results concerning stemness markers, since we noticed a trend of increase of OCT4 and SOX2 in both DPSC (Fig. 5A) and BM-MSC (Fig. 5B) cultured at $\mathrm{pHe} 6.5 \mathrm{vs.} \mathrm{pH}$ 7.4. This increase was also significant for SOX2 in BM-MSC.

\section{Extracellular acidosis maintained the stemness features of cells of mesenchymal origin}

The $24 \mathrm{~h}$ effect of extracellular acidosis on the stemness of mesenchymal cells was even more evident when we considered a longer exposure $(7 \mathrm{~d})$. In fact, spheres developed from DPSC (Fig. 6A) at an alkaline pHe were consistently fewer but larger compared to spheres formed at acidic pHe conditions. Moreover, the maintained stemness under acidic conditions was confirmed by the higher expression of canonical stemness-related genes. In particular, we observed a significantly higher expression of SOX2, OCT4, c-MYC and KLF4 in DPSC at acidic pHe (Fig. 6B). Similarly, the analysis performed by using a proteome profiler array of stem-related markers showed a trend for up-regulation for OCT4, SOX2, brachyury, nestin, CD38, E-cadherin and SOX17 in DPSC spheres cultured at low pHe vs. pHe 7.4 (Fig. 6C). When we compared the expression of the mentioned stem-related markers as a whole by paired analysis (spheres cultured at $\mathrm{pH} 6.5 \mathrm{vs}$. $\mathrm{pH} 7.4)$, this difference was highly significant $(p=0.0011)$.

Since DPSC derive from the cranial-derived neural crest cells, we evaluated the expression of nestin and p75/NGFR stem cell markers in DPSC exposed to acidic conditions ( $\mathrm{pHe} 6.5$ ). Also in this case, we found a trend for a higher expression of $\mathrm{p} 75 / \mathrm{NGFR}$ and nestin in DPSC at $\mathrm{pHe} 6.5$ respect to $\mathrm{pH} 7.4$, at both $24 \mathrm{~h}$ (Fig. 7A) and $7 \mathrm{~d}$ (Fig. 7B). The increased expression of nestin was significant at $7 \mathrm{~d}$. Similarly to DPSC, the floating spheres derived from BM-MSC at pHe 6.8, 7.1 and 7.4 were larger, but fewer in comparison to spheres maintained at lower pHe (Fig. 8A) and the stem related genes OCT4 and SOX2 were also significantly induced (Fig. 8B).

Extracellular acidosis sustains a quiescent state in stem cells of mesenchymal origin

Through deep-sequencing analysis of BM-MSC, in addition to the promotion of a stem cell-like phenotype, we observed the induction in acidic $\mathrm{pHe}$ of anti-apoptotic genes. Thus, we ascertained the effect of low $\mathrm{pH}$ on cell apoptosis and proliferation by using specific functional assays. A low pHe induced a significant decrease of DPSC cell number (Fig. 9A), but this was not associated with an increase of cell death, as the percentage of apoptotic cells was significantly lower at pHe 6.5 than at pHe 7.4 (Fig. 9B). Instead, the reduction of cell proliferation was correlated with a lower number of cycling cells, as revealed by the Ki67 index that significantly decreased in a pH-dependent manner (Fig. 9C). In particular, cells cultured at low $\mathrm{pH}$ accumulated in the G0 phase, instead of the S phase (Fig. 9D). A specific phase for quiescent stem cells, named as G0 alert, characterised by a larger cell size, has been described (Rodgers et al., 2014). Notably, under our experimental conditions, exposure to an acidic medium ( $\mathrm{pHe}<7.4$ ) significantly increased the diameter of DPSC (Fig. 9E), suggesting a transition from the G0 to the G0 alert phase. Similarly, we confirmed in BM-MSC that the Ki67 index was decreased at acidic pHe (6.5) (Fig. 10A) and that the reduced proliferation rate was not a result of apoptosis induction (Fig. 10C): the percentage of apoptotic cells at pHe 6.5 was significantly lower than the one measured at neutral pHe. Again, the cells size of BM-MSC was increased at low pHe (Fig. 10B).

\section{Pre-conditioning with extracellular acidosis retained the DPSC multilineage potential}

In order to investigate the impact of a transient exposure to the acidic microenvironment on clonal efficiency and multilineage potential of stem cells of mesenchymal origin, we exposed DPSC to pHe 6.5 or 7.4 for $7 \mathrm{~d}$, and then, after additional 10 and $21 \mathrm{~d}$ at physiological pHe conditions, we evaluated DPSC colony forming ability and multilineage differentiation. The multilineage potential was evaluated as osteogenic, adipogenic and chondrogenic differentiation by alizarin red stain, Oil Red O stain (lipid vacuoles quantification) and proteoglycan synthesis, respectively. In DPSC, clonogenic potential was significantly augmented (Fig. 11A), whereas the ability to differentiate into osteoblasts and adipocytes was similar independently of the pre-conditioning at acidic pHe (Fig. $11 \mathbf{B}, \mathbf{C})$. Conversely, the chondrogenic differentiation was significantly increased in DPSC pre-cultured at pHe 6.5 (Fig. 11D).

\section{Discussion}

For bone regenerative approaches, the bone marrow is the most widely used and obvious source for stem cells of mesenchymal origin, as it contains BM-MSC (Al-Nbaheen et al., 2013). DPSC are another population of mesenchymal stem cells that also exhibit a high osteogenic potential (Ledesma-Martínez et al., 2016; Mitsiadis et al., 2015). In this study, we used both BM-MSC and DPSC as models of osteogenic mesenchymal stem cells to observe the impact on their stemness and bone regeneration potential of acidic pHe levels that mimic the environmental conditions of cancer (Martin and Jain, 1994) and inflammation (Dong et al., 2013). 
As previously shown by Kohn et al (2002), we confirmed that an acidic $\mathrm{pHe}$ inhibits osteogenic differentiation and mineralisation. Indeed, after one week of treatment in an acidic microenvironment, the expression of osteoblast-related genes (i.e. type I collagen, alkaline phosphatase and RUNX2) was significantly reduced in DPSC. However, this inhibition was transient, as, at $14 \mathrm{~d}$, no significant differences in osteoblast-related gene expression were observed among cells maintained at different $\mathrm{pHe}$. On the contrary, in both DPSC and BMMSC models, the synthesis and release of extracellular matrix proteins (i.e. osteocalcin and type I collagen) were persistently impaired when cells were incubated under extracellular acidosis. With a completely opposite trend in respect to the other examined genes associated with mesenchymal differentiation, the transcriptional factor SOX9, involved in cartilage formation and chondrocyte differentiation (Noda et al., 1998), showed a trend for increase in DPSC cultured at an acidic pHe. In conclusion, in DPSC the downregulation of RUNX2, combined with a slight increment of SOX9 expression, suggests a less differentiated osteogenic phenotype. The significantly reduced ability of both DPSC and BM-MSC to deposit mineralised matrix at an acidic pHe is not surprising, as it may possibly derive from a decreased alkaline phosphatase activity and an increased solubility of hydroxyapatite at low $\mathrm{pH}$, as previously and elegantly demonstrated by Arnett (2008). However, the modulation of metabolism of mesenchymal stem cells by extracellular acidosis is another intriguing explanation. Indeed, short-term exposure to $\mathrm{pH} 6.5$ is sufficient to inhibit glycolysis in mesenchymal cells (Chano et al., 2016) and changes in cell metabolism have been recently associated with an indirect control of cell differentiation (Agathocleous et al., 2013). Then, we investigated if the biological effect on cell differentiation was an indirect result of the induction of apoptosis, stress or cell senescence as a result of extracellular acidosis. In BM-MSC, we did not find any significant difference in the expression of senescence related genes, while the expression of genes related to stress response was significantly increased, confirming our previous results (Avnet et al., 2017). Moreover, as we have already demonstrated in cancer cells of mesenchymal origin (Avnet et al., 2013; Avnet et al., 2016), acidic pHe did not increase cell apoptosis in normal cells of the same origin: short-term exposure to acidic $\mathrm{pHe}$ induced the expression of anti-apoptotic genes and the expression of pro-apoptotic genes was not affected. In addition, the number of apoptotic cells with pyknotic nuclei in DPSC and BM-MSC cultures was significantly reduced at $\mathrm{pH} 6.5$ vs. $\mathrm{pH}$ 7.4. Thus, cells maintained at an acidic $\mathrm{pH}$ were neither apoptotic nor senescent. Therefore, we assumed that the reduction of cell differentiation, and, as we observed later on, also of cell proliferation under acidosis, was rather a consequence of the maintenance of the cell into a stem-like phenotype and that extracellular acidosis was a stress environmental stimulus that modulates the stem cell fraction. Indeed, among the external stimuli, extracellular $\mathrm{pH}$ changes occur in a variety of physiological and pathological conditions, such as hypoxia, trauma and inflammation. As further evidence, we recently found that extracellular acidosis promotes the activation of the NF-kB pathway in BM-MSC (Avnet et al., 2017). The NF-kB pathway regulates cellular responses to external stress stimuli, like oxidative stress and inflammation and activates the transcription of pro-clonogenic and prostemness cytokines, including IL6 and IL8. The secretion of these strong immunomodulators leads to a positive autocrine feedback, whose regulation, in turn, might further maintain the stemness of mesenchymal stem cells. Also, deep sequencing analysis and qRT-PCR analysis suggested the maintenance of a stem-like phenotype when these cells were exposed to extracellular acidosis. Accordingly, when we analysed the ability of DPSC and BM-MSC to form floating spheres/spheroids, we found that an acidic stimulus favoured the development of spheres from
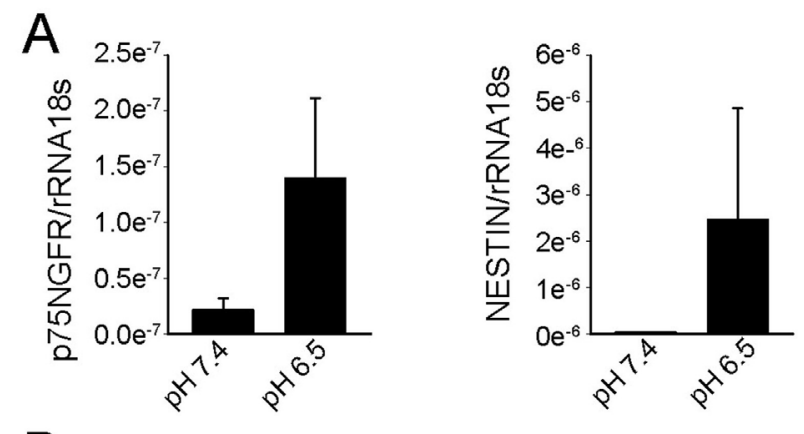

B

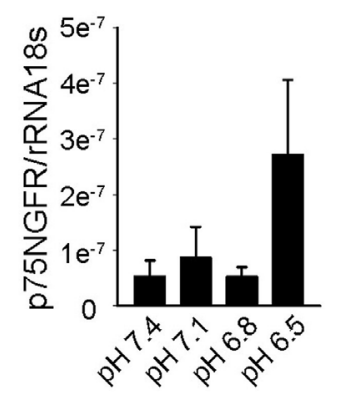

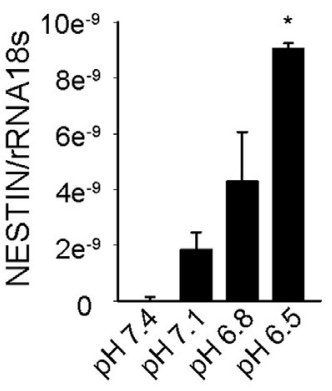

Fig. 7. Effect of extracellular acidosis on the expression of neuronal markers in DPSC. Real Time PCR analysis of the expression of p75/NGFR and nestin in DPSC cultured at different pHe at (A) $24 \mathrm{~h}$ and (B) $7 \mathrm{~d}$ (results obtained with three different donors and with two technical replicates, ${ }^{*} p<0.05$ vs. pHe 7.4). 
mesenchymal stem cells. Spheres are three-dimensional aggregates that mimic a physiological tissue niche (Ho et al., 2016). Within spheres, cells are characterised by enhanced stemness and delayed replicative senescence (Cesarz and Tamama, 2016). Further, when we looked at the expression of those canonical stemness-related genes that can reprogram somatic cells into induced pluripotent stem cells (IPs) (Takahashi et al., 2007), we found a strong induction of the expression of SOX2 and OCT4 in both DPSC and BM-MSC. Of note, the expression of c-MYC, that is not modulated to maintain the stemness-like state in BM-MSC (Roson-Burgo et al., 2014), was unaffected by a low $\mathrm{pHe}$. As DPSC originate from the cranial-derived neural crest cells, we also investigated the expression of the neuronal stem-related markers nestin and p75/NGFR (Mitsiadis et al., 2015; Martens et al., 2012) after exposure to acidic conditions. Similarly to the other mentioned stemrelated markers, these genes were induced by $\mathrm{pHe} 6.5$. Finally, following protein analysis, the concentration of stem-related markers brachyury, CD38, E-cadherin, nestin, OCT4, SOX17 and SOX2 in DPSC spheres grown at acidic pHe appeared to be positively regulated.

The stem cell phenotype has been associated with a reduction of proliferation and a tendency to dormancy, in order to preserve key functional features (Rodgers et al., 2014). Thus, we hypothesised that extracellular acidosis may also be a stimulus for the maintenance of a quiescent state in stem cells of mesenchymal origin. Indeed, we
A
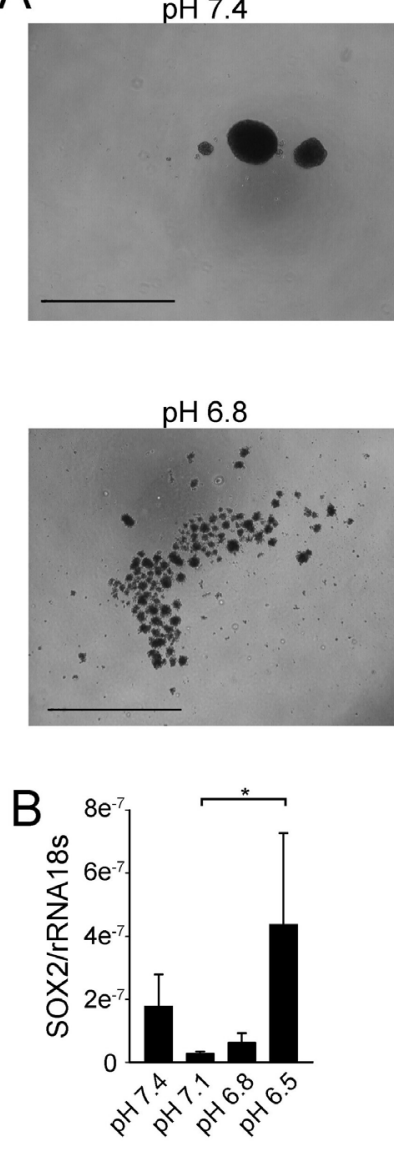

$\mathrm{pH} 7.1$
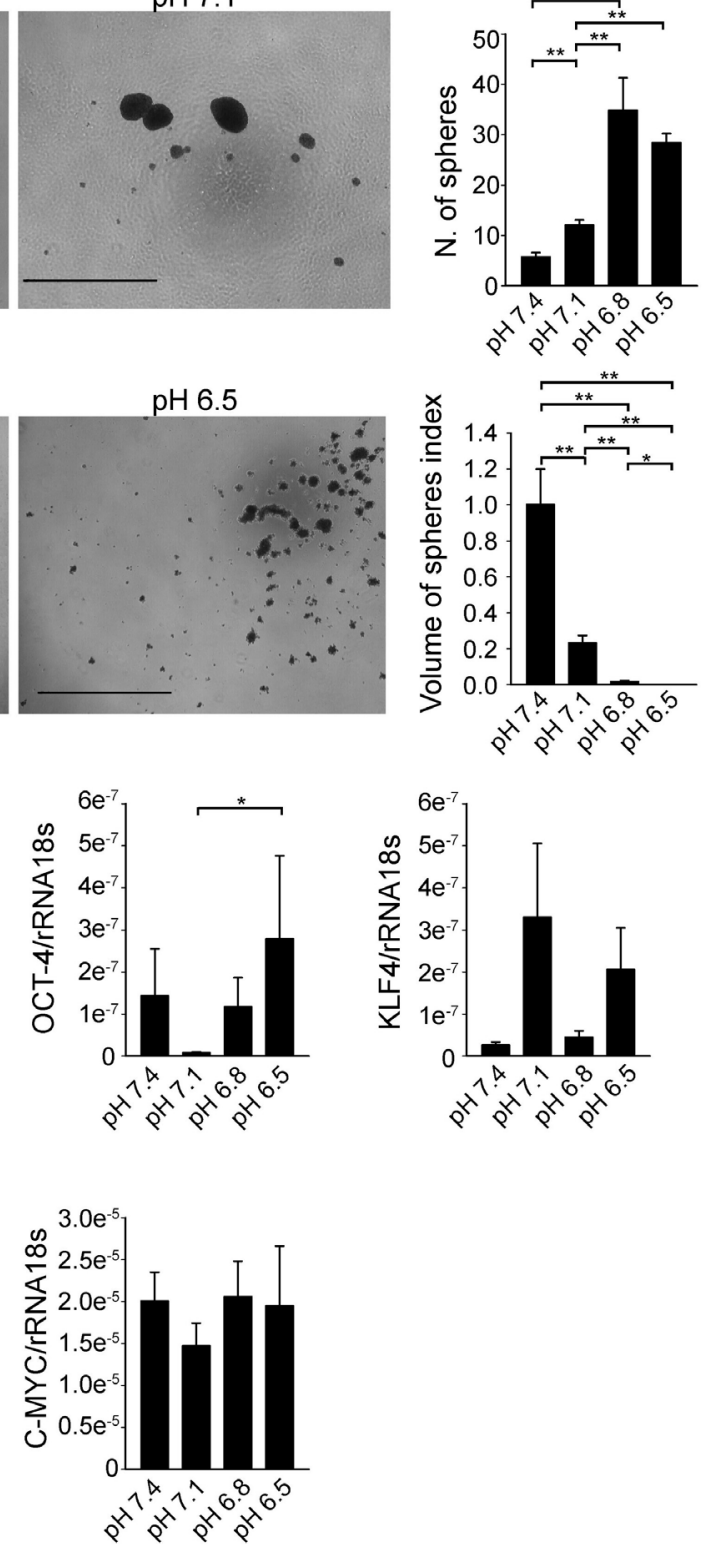

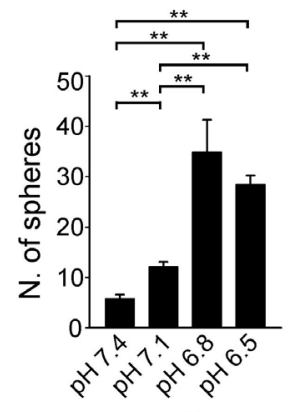

Fig. 8. Effect of extracellular acidosis on the stemness of BM-MSC. (A) Representative images of BM-MSC
spheres obtained after $10 \mathrm{~d}$ of culture in medium at different $\mathrm{pH}$ (left panel, scale bar $=500 \mu \mathrm{m}$ ). Right panel, quantification of number and volume index of spheres (results obtained with three different donors and with three technical replicates, mean $\pm \mathrm{SE}, * p<0.05, * * p<0.01$ ). (B) Real Time PCR analysis of the expression of SOX2, OCT4, KLF4 and c-MYC of BM-MSC maintained at different $\mathrm{pH}$ for $7 \mathrm{~d}$ (results obtained with three different donors and with two technical replicates, mean $\pm \mathrm{SE} ; * p<0.05$ ). 

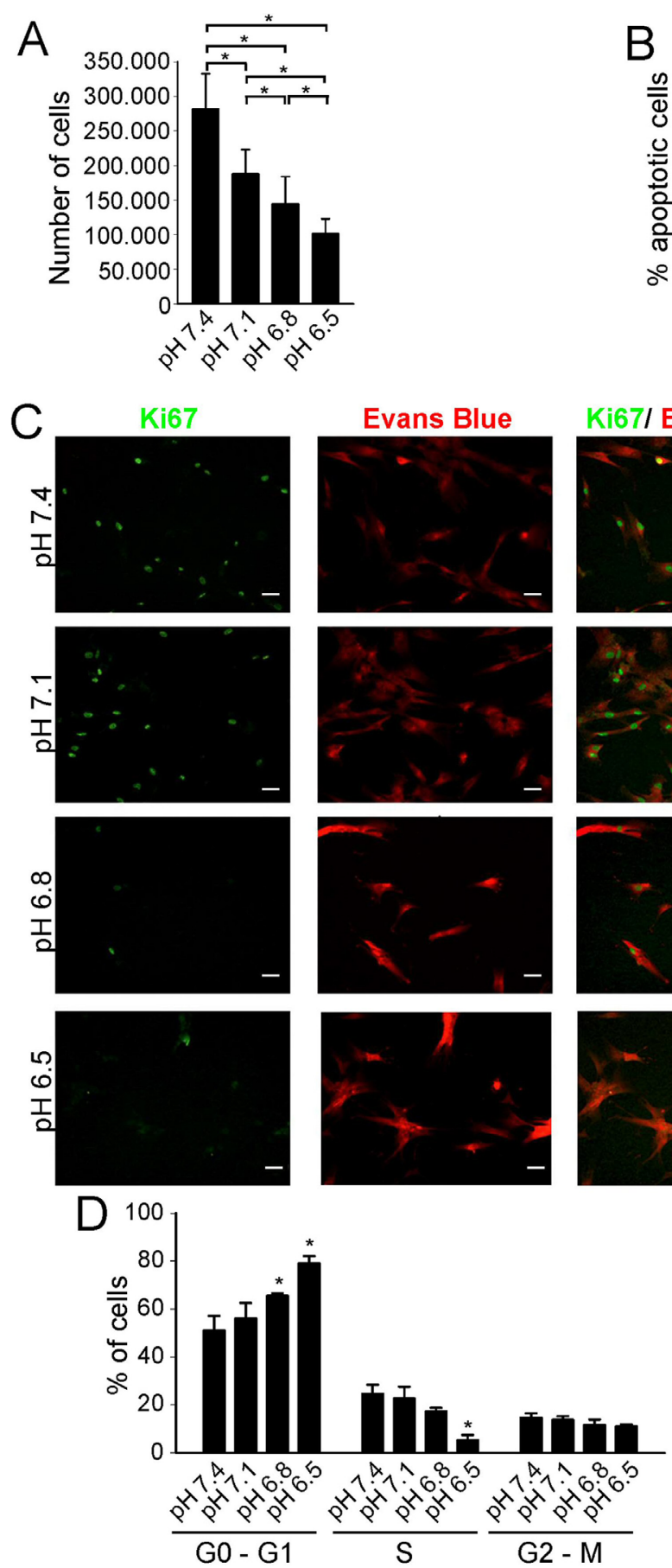

$\mathrm{B}$
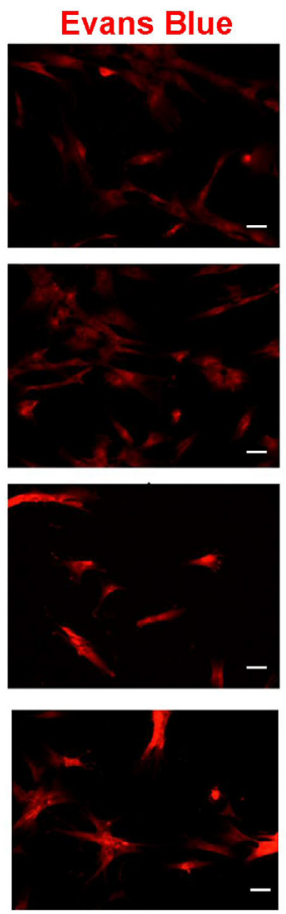

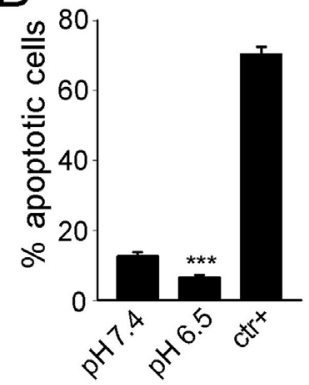

Ki67/ Evans Blue
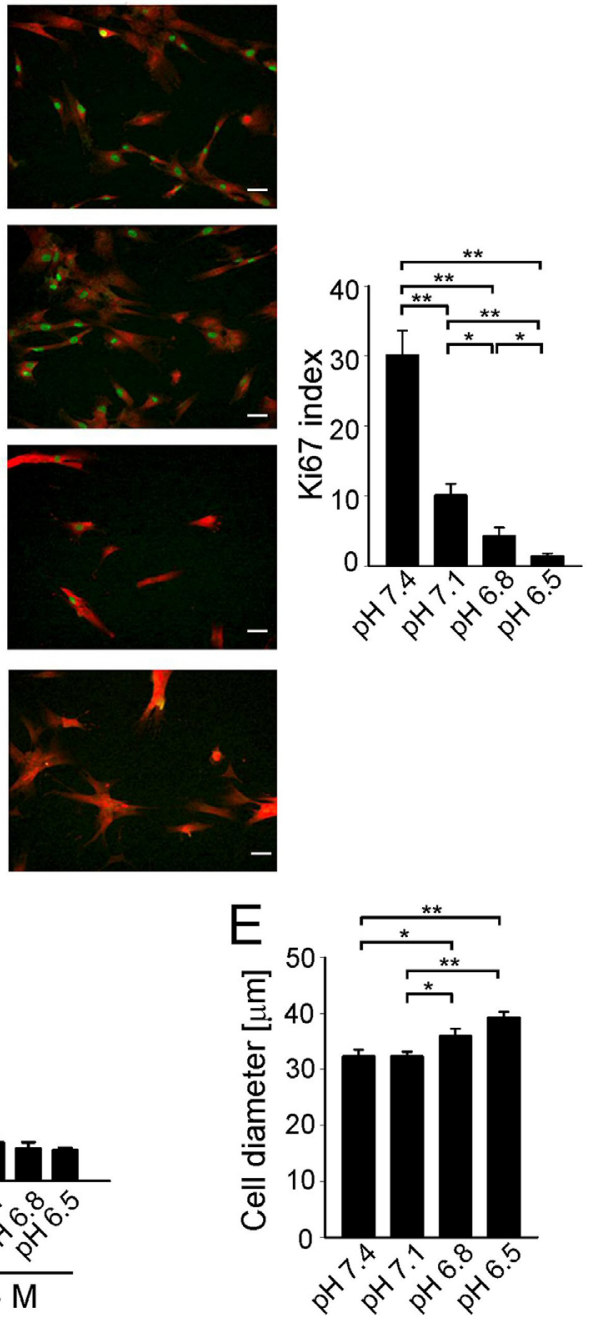

Fig. 9. Extracellular acidosis inhibited DPSC cell proliferation. Data are expressed as mean \pm SE. (A) DPSC were seeded and counted after $7 \mathrm{~d}$ of culture at different $\mathrm{pHe}$ (results obtained with three different donors and with two technical replicates, $* p<0.05, * * p<0.01$ ). (B) $\%$ of apoptosis measured by counting the pyknotic nuclei of DPSC cultured at pHe 6.5 and 7.4 for $7 \mathrm{~d}$ [staurosporine treatment was the positive control (results obtained with three different donors and with two technical replicates, *** $p<0.001$ vs. pHe 7.4)]. (C) Representative images of Ki67 staining of DPSC at different pHe (left panel). Nuclear Ki67 (green) and cytoskeletal staining by Evans blue (red), scale bar $=500 \mu \mathrm{m}$. Right panel, quantification of the Ki-67 index (results obtained with three different donors and with three technical replicates; ${ }^{*} p<0.05, * * p<0.01$ ). (D) Cell cycle distribution of DPSC, after exposure to different $\mathrm{pHe}$ for $36 \mathrm{~h}$ (results obtained with three different donors; ${ }^{*} p<0.05$ vs. $\mathrm{pH} 7.4$ ). (E) Quantification of cell size as a marker of the G0 phase alert status (results obtained with three different donors and with three technical replicates, $* p<0.05, * * p<0.01)$. 
found a significantly decreased number of proliferating cells that, as previously commented, cannot be ascribed to a pro-apoptotic effect of acidic $\mathrm{pHe}$, but rather correspond to an increased number of cells in G0 phase. The effect of pHe on cell cycle progression had already been documented (Gillies and Deamer, 1979). Interestingly, a recent characterisation of the G0 phase has revealed a more specific phase for quiescent stem cells, named as G0 alert. This phase is characterised by a larger cell size with an increased protein content that is needed for a prompt entry into the cell cycle (Rodgers et al., 2014). Indeed, transition from the G0 state to an actively cycling state is paramount to ensure rapid regeneration. Notably, exposure to an acidic pHe increased the diameter of both DPSC and BM-MSC, suggesting that, when maintained in an acidic microenvironment, mesenchymal stem cells enter into a G0 alert phase. Indeed, acidosis is a rapid and heavily stressing stimulus associated with injury and inflammation and this may have a major role in triggering the bone regenerative process.

Finally, we explored if pre-conditioning in acidic pHe had an effect on the multilineage potency of DPSC. With this aim, DPSC were pretreated with acidic $\mathrm{pHe}$ and seeded for colony forming unit assay and osteogenic, chondrocytic and adipogenic differentiation assays. DPSC showed an increased ability to form CFU when pretreated with extracellular acidosis and were still fully competent for multilineage differentiation.

Altogether, our data strongly support the concept that extracellular acidosis allows the maintenance of stemness in mesenchymal cells, as previously demonstrated in cancer cells (Hjelmeland et al., 2011) and suggest that lowering the extracellular $\mathrm{pH}$ is a key microenvironmental parameter to maintain the stem cell niche. The acid-induced phenotype is correlated with maintenance of stemness that is permissive for survival, with high cytoprotective activity as a response to the stressing condition. Thus, we propose that, under short-term acidosis, mesenchymal stem cells use a mechanism of stemness maintenance to acquire a higher degree of functionality for regeneration at the site of injury or inflammation, with increased expression of stem-related markers and cloning efficiency. A similar mechanism, mediated by hypoxia, has already been demonstrated in embryonic stem cells (Das et al., 2012). In the case of chondrogenic differentiation, we observed that the pre-conditioning of DPSC in the acidic $\mathrm{pH}$ promoted the synthesis of proteoglycans. Articular chondrocytes reside in an acidic and hypoxic environment in vivo (Das
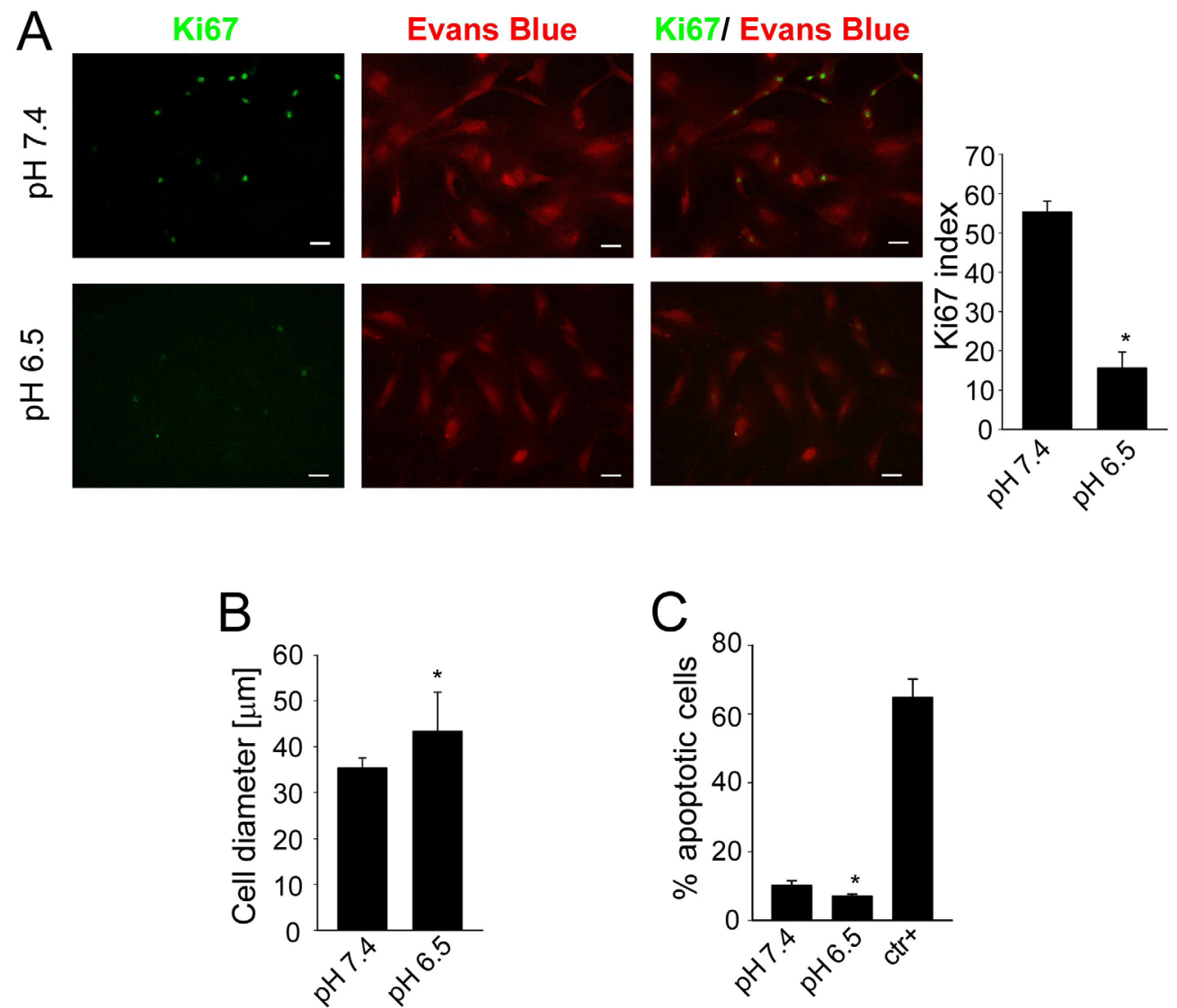

Fig. 10. Extracellular acidosis inhibited BM-MSC cell proliferation. Data are expressed as mean \pm SE. (A) Representative images of Ki67 staining of BM-MSC at different pHe (left panel). Nuclear Ki67 (green) and cytoskeletal staining by Evans blue (red), scale bar $=500 \mu \mathrm{m}$. Right panel, quantification of the Ki-67 index (results obtained with two different donors and with three technical replicates; $* p<0.05$ ). (B) Quantification of cell size as a marker of the G0 phase alert status (results obtained with two different donors and with two technical replicates, $* p<0.05$ ). (C) \% of apoptosis measured by counting the pyknotic nuclei of BM-MSC cultured at pHe 6.5 and 7.4 for $7 \mathrm{~d}$. Staurosporine treatment was the positive control (results obtained with two different donors and with two technical replicates, $* p<0.05$ vs. pHe 7.4). 
A

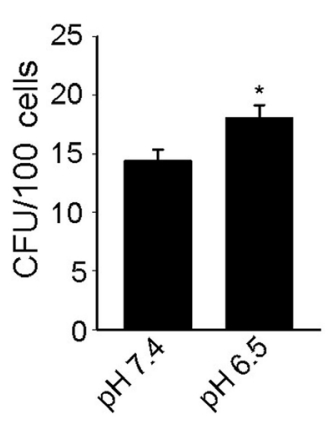

C

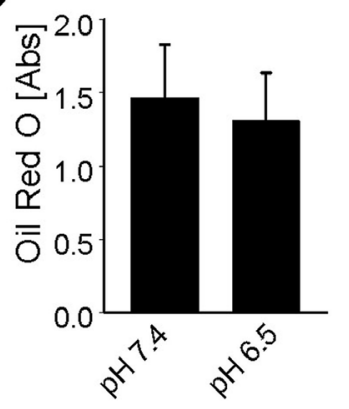

$\mathrm{B}$

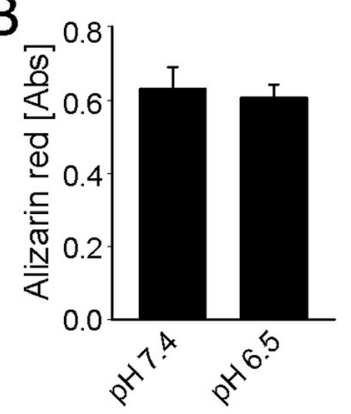

$\mathrm{D}$

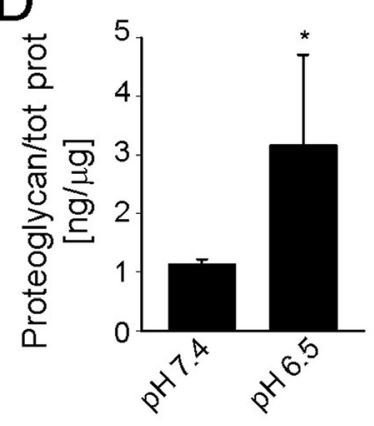

Fig. 11. Acidic pre-conditioning retained the DPSC multilineage potential. Data are expressed as mean \pm SE. (A) Colony forming unit (CFU-F) assay in DPSC pre-exposed to neutral or acidic $\mathrm{pHe}$ for $7 \mathrm{~d}$ (results obtained with two different donors and with two technical replicates; $* p<0.05)$. (B) Osteogenic differentiation. Quantification of alizarin red staining (absorbance at $570 \mathrm{~nm}$ ) (results obtained with three different donors and with two technical replicates). (C) Adipogenic differentiation. Quantification of Oil Red O staining (absorbance at $540 \mathrm{~nm}$ ) (results obtained with three different donors and with two technical replicates). (D) Chondrogenic differentiation. Quantification of sulphated glycosaminoglycan levels normalised to total protein content (results obtained with three different donors and with two technical replicates; $* p<0.05)$.

et al., 2010) and extracellular acidity is an important regulator of cartilage matrix metabolism and activity. Matrix acidification could provide a way of regulating proteoglycan synthesis by a negative feedback system (Hall et al., 1996). Moreover, pHe values below 6.5 have been detected in pathological conditions and associated with a lower glycosaminoglycans content (Kitano et al., 1993). Thus, it may be speculated that pre-treatment with low $\mathrm{pHe}$ is perceived by undifferentiated chondrocytes as an injuryassociated stimulus (loss of proteoglycan composition of the cartilage matrix, local inflammation or deep hypoxia), triggering cartilage regeneration when the $\mathrm{pHe}$ normalises with the disappearance of inflammation. Similarly to the speculated effect of acidosis of chondrocyte differentiation and cartilage, during the early phases of bone healing, a subsequent phase of alkalinisation is likely to occur so that successful bone differentiation and regeneration develops. Indeed, delayed union and infection are often associated with persistent local acidity (Newman et al., 1987) and it is likely that a low pHe may contribute to the delayed or reduced healing of fractures in diabetic subjects.

To date, over 400 clinical trials are exploring the use of cell therapy with mesenchymal stem cells for different conditions (Liu and Ma, 2015) associated with local acidosis, including inflammation (Dong et al., 2013), bone fracture (Newman et al., 1987) and intervertebral disc degeneration (Urban, 2002). We suggest that modulation of local pHe might be beneficial to increase the effectiveness of these strategies.

\section{Conclusions}

We provide evidence that an acidic microenvironment promotes the maintenance of stemness of osteogenic mesenchymal stem cells through the induction of stemnessrelated genes and a quiescent cell cycle status.

\section{Acknowledgments}

Financial support by the Italian Ministry of the Health, financial support for scientific research "5 per mille 2012" (to NB), financial support by the Regione Emilia Romagna, Programma di Ricerca Regione-Università 2010-2012 - Strategic Programme 'Regenerative medicine of cartilage and bone' (to NB), financial support by the Italian Association for Cancer Research (AIRC IG 15608) (to NB), financial support by the University of Zurich (to TAM) was received. AM performed part of this work (three months) at the Institute of Oral Biology (University of Zurich), supervised by TAM. The authors declare no potential conflicts of interest.

\section{References}

Agathocleous M, Harris WA (2013) Metabolism in physiological cell proliferation and differentiation. Trends Cell Biol 23: 484-492.

Al-Nbaheen M, Vishnubalaji R, Ali D, Bouslimi A, Al-Jassir F, Megges M, Prigione, A, Adjaye J, KassemM, AldahmashA (2013) Human stromal (mesenchymal) stem cells from bone marrow, adipose tissue and skin exhibit differences in molecular phenotype and differentiation potential. Stem Cell Rev 9: 32-43.

Arnett TR (2008) Extracellular pH regulates bone cell function. J Nutr 138: 415S-418S.

Arnett TR (2010) Acidosis, hypoxia and bone. Arch Biochem Biophys 503: 103-109.

Avnet S, Di Pompo G, Lemma S, Salerno M, Perut F, Bonuccelli G, Granchi D, Zini N, Baldini N (2013) V-ATPase is a candidate therapeutic target for Ewing sarcoma. Biochim Biophys Acta 1832: 1105-1116.

Avnet S, Lemma S, Cortini M, Pellegrini P, Perut F, Zini N, Kusuzaki K, Chano T, Grisendi G, Dominici 
M, De Milito A, Baldini N (2016) Altered pH gradient at the plasma membrane of osteosarcoma cells is a key mechanism of drug resistance. Oncotarget 7: 63408-63423.

Avnet S, Di Pompo G, Chano T, Errani C, IbrahimHashim A, Gillies RJ, Donati DM, Baldini N (2017) Cancer-associated mesenchymal stroma fosters the stemness of osteosarcoma cells in response to intratumoral acidosis via $\mathrm{NF}-\kappa \mathrm{B}$ activation. Int $\mathrm{J}$ Cancer 140: 13311345.

Brandao-Burch A, Utting JC, Orriss IR, Arnett TR (2005) Acidosis inhibits bone formation by osteoblasts in vitro by preventing mineralization. Calcif Tissue Int 77: 167-174.

Castro F, Ferreira A, Roch F, Vicente A, Teixeira JA (2012) Characterization of intermediate stages in the precipitation of hydroxyapatite at $37^{\circ} \mathrm{C}$. Chem Eng Sci 77: 150-156.

Cesarz Z, Tamama K (2016) Spheroid culture of mesenchymal stem cells. Stem Cells Int 2016: 917635.

Chakkalakal DA, Mashoof AA, Novak J, Strates BS, McGuire MH (1994) Mineralization and pH relationships in healing skeletal defects grafted with demineralised bone matrix. J Biomed Mater Res 28: 1439-1443.

Chano T, Avnet S, Kusuzaki K, Bonuccelli G, Sonveaux P, Rotili D, Mai A, Baldini N (2016) Tumour-specific metabolic adaptation to acidosis is coupled to epigenetic stability in osteosarcoma cells. Am J Cancer Res 15: 859875.

Claes L, Recknagel S, Ignatius A (2012) Fracture healing under healthy and inflammatory conditions. Nat Rev Rheumatol 8: 133-143.

Das B, Bayat-Mokhtari R, Tsui M, Lotfi S, Tsuchida R, Felsher DW, Yeger H (2012) HIF-2 $\alpha$ suppresses p53 to enhance the stemness and regenerative potential of human embryonic stem cells. Stem Cells 30: 1685-1695.

Das RH, van Osch GJ, Kreukniet M, Oostra J, Weinans $\mathrm{H}$, Jahr H (2010) Effects of individual control of $\mathrm{pH}$ and hypoxia in chondrocyte culture. J Orthop Res 28: 537-545.

Dong L, Li Z, Leffler NR, Asch AS, Chi JT, YangLV (2013) Acidosis activation of the proton-sensing GPR4 receptor stimulates vascular endothelial cell inflammatory responses revealed by transcriptome analysis. PLoS One 8: e61991.

Gerweck LE, Seetharaman K (1996) Cellular $\mathrm{pH}$ gradient in tumor versus normal tissue: potential exploitation for the treatment of cancer. Cancer Res 56: 1194-1198.

Gillies R, Deamer DW (1979) Intracellular pH changes during the cell cycle in Tetrahymena. J Cell Physiol 100: 23-31.

Hall AC, Horwitz ER, Wilkins RJ (1996) The cellular physiology of articular cartilage. Exp Physiol 81: 535-545.

Hamm LL, Nakhoul N, Hering-Smith KS (2015) Acidbase homeostasis. Clin J Am Soc Nephrol 10: 2232-2242.

Hjelmeland AB, Wu Q, Heddleston JM, Choudhary GS, MacSwords J, Lathia JD, McLendon R, Lindner D, Sloan A, Rich JN (2011) Acidic stress promotes a glioma stem cell phenotype. Cell Death Differ 18: 829-840.

Hjelmeland AB, Wu Q, Heddleston JM, Choudhary GS, MacSwords J, Lathia JD, McLendon R, Lindner D,
Sloan A, Rich JN (2011) Acidic stress promotes a glioma stem cell phenotype. Cell Death Differ 18: 829-840.

Ho SS, Murphy KC, Binder BY, Vissers CB, Leach JK (2016) Increased survival and function of mesenchymal stem cell spheroids entrapped in instructive alginate hydrogels. Stem Cells Transl Med 5: 773-781.

Kitano T, Zerwekh JE, Usui Y, Edwards ML, Flicker PL, Mooney V (1993) Biochemical changes associated with the symptomatic human intervertebral disk. Clin Orthop Relat Res 293: 372-377.

Kohn DH, Sarmadi M, HelmanJ, Krebsbach PH (2002) Effects of $\mathrm{pH}$ on human bone marrow stromal cells in vitro: implications for tissue engineering of bone. J Biomed Mater Res 60: 292-299.

Kraut JA, Madias NE (2010) Metabolic acidosis: pathophysiology, diagnosis and management. Nat Rev Nephrol 6: 274-285.

Ledesma-Martínez E, Mendoza-Núñez VM., SantiagoOsorio E (2016) Mesenchymal stem cells derived from dental pulp: a review. Stem Cells Int 2016: 4709572.

Liu Y, Ma T (2015) Metabolic regulation of mesenchymal stem cell in expansion and therapeutic application. Biotechnol 31: 468-481.

Livak KJ, Schmittgen TD (2001) Analysis of relative gene expression data using real-time quantitative PCR and the $2 \Delta \Delta \mathrm{CT}$ method. Methods 25: 402-408.

Martens W, Wolfs E, Struys T, Politis C, Bronckaers A, Lambricht I (2012) Expression pattern of basal markers in human dental pulp stem cells and tissue. Cells Tissues Organs 196: 490-500.

Martin GR, Jain RK (1994) Noninvasive measurement of interstitial $\mathrm{pH}$ profiles in normal and neoplastic tissue using fluorescence ratio imaging microscopy. Cancer Res 54: 5670-5674.

McAdams TA, Miller WM, Papoutsakis ET (1997) Variations in culture $\mathrm{pH}$ affect the cloning efficiency and differentiation of progenitor cells in ex vivo haemopoiesis. Br J Haematol 97: 889-895.

Mitsiadis TA, Orsini G, Jimenez-Rojo L (2015) Stem cell-based approaches in dentistry. Eur Cell Mater 30: 248-257.

Mohyeldin M, Garzón-Muvdi T, Quiñones-Hinojosa A (2010) Oxygen in stem cell biology: a critical component of the stem cell niche. Cell Stem Cell 7: 150-161.

NewmanRJ, Stone MH, Mukherjee SK (1987) Accelerated fracture union in association with severe head injury. Injury 18: 241-246.

Noda M, Nifuji A, Tuji K, Furuya K, Ichiro S, Asou Y, Kawaguchi N, Yamachita K (1998) Transcription factors and osteoblasts. Front Biosci 1: d817-820.

Obokata H, Wakayama T, Sasai Y, Kojima K, Vacanti MP, Niwa H, Yamato M, Vacanti CA (2014) Retraction: stimulus-triggered fate conversion of somatic cells into pluripotency. Nature 511: 112.

Orriss IR, Key ML, Hajjawi MO, Millán JL, Arnett TR (2015) Acidosis is a key regulator of osteoblast ectonucleotidase pyrophosphatase/phosphodiesterase 1 (NPP1) expression and activity. J Cell Physiol 230: 3049-3056.

Rodgers JT, King KY, Brett JO, Cromie MJ, Charville GW, Maguire KK, Brunson C, Mastey N, Liu L, Tsai 
CR, Goodell MA, Rando TA (2014) mTORC1 controls the adaptive transition of quiescent stem cells from $\mathrm{G} 0$ to G(Alert). Nature 510: 393-396.

Rosner M and Hengstschläger M (2011) mTOR protein localization is cell cycle-regulated. Cell Cycle 10: 36083610 .

Roson-Burgo B, Sanchez-Guijo F, Del Cañizo C, De Las Rivas J (2014) Transcriptomic portrait of human mesenchymal stromal/stem cells isolated from bone marrow and placenta. BMC Genomics 15:910-928.

Salerno M, Avnet S, Bonuccelli G, Hosogi S, Granchi D, Baldini N (2014) Impairment of lysosomal activity as a therapeutic modality targeting cancer stem cells of embryonal rhabdomyosarcoma cell line RD. PLoS One 9: e110340.

Takahashi K, Tanabe K, Ohnuki M, Narita M, IchisakaT, Tomoda K Yamanaka S (2007) Induction of pluripotent stem cells from adult human fibroblasts by defined factors. Cell 131: 861-872.

Takeuchi S, Hirukawa K, Togari A (2013) Acidosis inhibits mineralization in human osteoblasts. Calcif Tissue Int 93: 233-240.

Tirino V, Paino F, De Rosa A, Papaccio G (2012) Identification, isolation, characterization, and banking of human dental pulp stem cells. Methods Mol Biol 879: 443-463.

Urban JP (2002) The role of the physicochemical environment in determining disc cell behaviour. Biochem Soc Trans 30: 858-864.

\section{Discussion with Reviewer}

Drissi Hicham: Did the authors attempt to demonstrate pluripotential of the cells that expressed high pluripotence markers in response to $\mathrm{pH}$ 6.5? Can these cells induce teratoma in vivo? Can multipotent mesenchymal cells stem from these cells?

Authors: The hypothesis that acidic microenvironment can be per se a stimulus for the formation of different type of tissues starting from the same stem cell is very intriguing and challenging, also taking into account the recent Obokata report withdrawal (Obokata et al., 2014), and demands for careful consideration. However, although we found that pluripotential markers, as well as colony forming efficiency, are upregulated by extracellular acidosis, to date, there is no evidence that these microenvironmental features are sufficient to prompt teratoma formation in vivo. Still, in our study, we tested if the preliminary short-exposure to low extracellular $\mathrm{pH}$ was sufficient to affect the differentiating potential of mesenchymal stem cells and we did not observe any effect on osteogenic and adipogenic potentials. The lack of effect of acidosis on the ability of stem cells to differentiate into different tissues might imply that a longer and chronic exposure to acidosis is required to observe such phenomenon. Thus, this type of analysis necessarily will require a completely different experimental approach, including the on purpose set-up of preclinical models.

Editor's note: The Scientific Editor responsible for this paper was Juerg Gasser. 